\title{
Think tank capacity building on tobacco economics: experiences and lessons learnt
}

\author{
Erika Siu (10 , Frank J Chaloupka, Evan Blecher
}

University of Illinois, Chicago, Illinois, USA

\section{Correspondence to}

Erika Siu, University of Illinois at Chicago, Chicago, Illinois, USA; erikas@uic.edu

Received 14 August 2019 Revised 17 December 2019 Accepted 6 January 2020
A) Check for updates

(C) Author(s) (or their employer(s)) 2020. No commercial re-use. See rights and permissions. Published by BMJ.

To cite: Siu E, Chaloupka FJ, Blecher E. Tob Control 2020:29:s289-s292.

\section{INTRODUCTION}

The article describes the Tobacconomics project, 'Accelerating Progress on Tobacco Taxes in Lowand Middle-Income Countries' and the capacity building model used by the Tobacconomics team to develop core competencies in economic analysis among think tank partners, whose research is presented in this supplement. Between 2017 and 2019, the Tobacconomics team at the University of Illinois at Chicago, a partner of the Bloomberg Initiative To Reduce Tobacco Use, partnered with 27 policy research institutions (called 'think tanks' in this article) in low-income and middle-income countries (LMICs). This supplement contains selected research on the economics of tobacco control from our partners. This overview article describes the capacity building model used by the Tobacconomics team. The article also shares experiences and lessons learnt thus far.

\section{PROJECT OVERVIEW}

This Tobacconomics project, Accelerating Progress on Tobacco Taxes in Low-and Middle-Income Countries (grant number KC 085918) is funded at approximately US $\$ 4$ million per year by Bloomberg Philanthropies as part of the Bloomberg Initiative to Reduce Tobacco Use. (The views expressed in this document cannot be attributed to, nor do they represent, the views of University of Illinois at Chicago, the Institute for Health Research and Policy, or Bloomberg Philanthropies.) The project supports research efforts to establish evidence-based tobacco tax systems. It is a capacity building project, but decidedly issue-specific. Significant increases in cigarette and other tobacco product taxes are the most effective and cost-effective policy for reducing the death, disease and economic consequences of tobacco use. Evidence from numerous countries around the world demonstrates that increases in taxes that raise prices lead current users to quit, reduce consumption among continuing users and are particularly effective in preventing uptake among young people. At the same time, these taxes are an efficient mechanism for increasing government revenue. ${ }^{1-5}$

The project responds to the need for locally produced and high-quality economic evidence by investing in the capacity of incountry think tanks focused on economic and fiscal policy. An important sustainability principle of the project is the necessity of a partnership with an institution, rather than short-term contracts with individual experts. By establishing a medium-term (up to 5 years) partnership with a think tank, foundational skills in the economics of tobacco control are established within an institution. One of the additional benefits is that these skills are transferable to other areas of fiscal and economic policy, for example, alcohol, nutrition, environment, and so on. Moreover, the project builds research capacity, and focuses on dissemination and strategic policy engagement skills with the aim of understanding the local channels of knowledge into policy making, illustrated in box 1 , thus establishing critical relationships with relevant stakeholders. $^{6}$

\section{Research thus far}

Depending on the evidence gaps within a given country, research for the first grant period focused on demand elasticity estimations, that is, consumer behavioural responses to price increases of tobacco products. Most of the papers contained in this supplement- from Argentina, Bosnia, Croatia, Kosovo, Montenegro, Serbia, and Pakistan (SED1) -include demand elasticity estimations using various data sources and methods. In all cases secondary data analysis was required for these estimations, which were typically used as inputs into simulation models to project impacts of tax increases on government revenues and consumption of tobacco products. The authors from Pakistan (SED2) took this analysis a step further to calculate elasticities among smokers and all households by income groups and subnational regions to increase the sophistication of the simulation model.

Researchers from Indonesia and Vietnam (SED3) conducted primary data collection to quantify the level of illicit trade and historical trends where previous estimations existed. These are published together with other research in a Tobacco Control supplement, "Measuring Illicit Trade in Tobacco Products" $"$. The authors from Brazil (SED4) analyse previous estimates of illicit trade and the cross-border trade flows of cigarette inputs between Paraguay and Brazil, which may improve tax administration efforts to curb illicit trade in Brazil. Finally, authors in Pakistan (SED5) also examined supply side aspects of the tobacco industry, specifically, how tobacco tax increases affect macroeconomic factors like employment, agricultural output and economic growth. All research included in this supplement was published by the institutions in research reports and policy briefs and presented at national-level conferences and meetings with policy makers, media and public health advocates. 
Box 1 Research informing policy: an example from Pakistan

A notable illustration of the knowledge to policy making process is currently underway in Pakistan, where Tobacconomics works with two think tanks-the Pakistan Institute for Development Economics (PIDE) and Social Policy Development Centre (SPDC). In 2018, the first year of the capacity building partnership, PIDE and SPDC produced solid research disseminated through reports, briefs and two conferences. The research recommended elimination of the third tax tier and increased tax rates based on economic analysis of behavioural responses to tax increases, prevalence analysis and examination of the broader economic impacts of tax increases. The research was picked up by media and government officials, and resulted in direct, rapid response policy consultations at the request of the Federal Bureau of Revenue. Along with the concerted advocacy efforts of the tobacco control community, the think tanks' research outcomes were reflected in the government's new budget with the removal of the third tax tier and increased rates in both the remaining tax tiers. Since the tax reform, SPDC has evaluated the impacts on consumption and government revenues and communicated the analysis to all stakeholders, including the government.

\section{LESSONS LEARNT}

This overview article is not an independent evaluation of the project. Rather, since the authors have been directly involved in the implementation of this project, the article's purpose is to provide an overview of the research contained within the supplement and to provide an explanation of the work, how it is situated in the capacity building/international development fields and reflections on lessons learnt during the first 3 years, which are listed below.

1. Capacity building is a time intensive process and requires close monitoring. Given that many economic policy think tanks have never worked in the economics of tobacco control, the research capacity requires close mentoring and a steady stream of technical assistance, either through inperson training, interactive workshops, periodic research meetings of multiple think tanks in the same region or regular communication. Although research quality is always paramount, for the purposes of this project, research quality is particularly important because one of the main target audiences on tobacco taxation is ministry of finance. Therefore, before the think tank's results are disseminated, they must be robust. Given that the think tanks are often new entrants, and ministries of finance can be very sceptical of economic policy outputs from NGOs, it is prudent to take the steps necessary to help the think tank produce a quality research product first before engaging in dissemination.

2. Mentored research cannot be outsourced. Having a staff economist as the primary contact for each of the think tanks has been essential to ensuring that think tanks have access to technical assistance at each step of the way. Toolkits and inperson training workshops can be provided by outside consultants when necessary, however, team economists provide technical guidance on a regular basis. Outside experts may not have the same commitment to skills transfer and quality of the end product, in which case, the project runs the risk of having the outside consultant doing the economic analysis work, with limited knowledge and technical skills transfer. Mentoring and building capacity require a specific skill set, and a clear understanding of capacity building roles, which the team economists have grown into over the past three years. ${ }^{89}$ It is important to note that each Site Lead has extensive knowledge of the region in which they are working; in most cases it is their land of origin. As noted by Datta et $a l$, this is often an asset in understanding the local context and cultural sensitivities at play in the capacity building relationship. ${ }^{10}$

3. Quality takes time. A one year plan of work should provide enough time for the think tank to master one fundamental building block of research, for an example, estimating demand for tobacco products and possibly modelling revenue and consumption changes for alternative tax structures. Due to the fact that this is a new area of analysis for many economic policy think tanks, there is a steep learning curve, which requires a large time investment. Thus, it is best to work with manageable topics that build on previous research to build core competencies. In addition, access to quality data in many LMICs can be a time-consuming challenge. Many partners faced significant challenges accessing government data. In the first round of working with think tanks, about half of the think tank partners delivered quality products on time. In order to ensure timely delivery for the next grant period, the team is working with think tank partners to establish clearer deadlines in the scope of work. In addition, more time for review of product drafts before the final deadline has also been allocated.

4. Direct involvement is best. We have learnt to insist on direct involvement with think tanks throughout the research process, even if operating through a regional network. This may create a challenging situation with the network lead think tank, but we found that it can work, as long as we are communicating transparently within the understanding of the capacity building relationship. In dealing with a regional network, it is also helpful to keep things simple where possible. For example, rather than having various research topics, it worked better for us to have the same research topic (assuming different countries) so that the training and technical assistance can be harmonised. It helps if the groups are at similar capacity levels, but this is not completely necessary as groups with higher capacity can work with others more easily.

\section{HOW TOBACCONOMICS CAPACITY BUILDING WORKS}

Tobacconomics think tank partnerships are directed by Frank Chaloupka, the leading expert on the economics of tobacco control. Each of the four regions (Latin America, south-eastern Europe, South Asia and south-east Asia) is managed by a team economist. The team also includes a dissemination manager, a grants administrator, and project manager. The team economists serve as Site Leads, and provide step-by-step technical assistance for the implementation of the research plan. Think tanks also receive technical assistance for effective dissemination and policy engagement. Through the Tobacconomics.org website, the team also publishes policy briefs, white papers and toolkits (among other products) in economic analysis to provide resources for researchers, advocates and policy makers.

\section{How research topics are selected}

Specific research topics and methods are developed in a research plan through a consultative process between the Tobacconomics team and the think tank partners. In each country, Tobacconomics economists develop a research matrix to identify recent 
Box 2 Core competencies model for capacity building

1. How will consumers respond to tax increases and other structural reforms?

- Estimating demand elasticity using household expenditure and other survey data; store scanner data; and/or time series data.

2. How will a given tax increase/reform affect the price of taxed and untaxed products and how will this change in price affect government revenues, consumption and health?

- Modelling alternative tax structures/rates on revenues and public health impacts.

3. How will tax increases/reforms affect the poor?

- Measuring distributional impacts of tax increases.

4. What are the health and economic costs of a given unhealthy behaviour and how can tax increases/reforms address these costs?

- Quantifying economic costs (direct and indirect) of use and how taxes can address these costs.

5. How will tax increases/reforms affect employment and economic growth?

- Estimating macroeconomic impacts of tax increases, for example, employment, economic growth, supply chain analysis, and so on, through quasi-experimental designs, input-output, computable general equilibrium, and other models.

6. To what extent do taxes lead to tax avoidance and evasion?

- Quantifying extent of cross-border shopping in tax evaluation models.

- Quantifying levels of illicit trade, measuring trends, geographical areas of leakage, and so on, using primary and secondary data sources.

research on the economics of tobacco control, and significant evidence gaps. The team also works with external partners, international institutions, government and country tobacco control experts to identify priority areas for research based on policy needs. In addition, the Tobacconomics team adopts an overall 'Core Competencies' strategy (box 2) of building the capacity. The core competencies are based on key questions that arise in debates around tobacco tax increases and reforms; and the core competencies are tools for answering those questions.

\section{How think tanks are selected}

During 2017, the first year of the project, the Tobacconomics team undertook a scoping of highly rated economic policy think tanks (depending on the country/region, 10-50) in the four regions. After shortlisting several think tanks (depending on the country/region, 10-20) through desk research and interviews over teleconference, the team met inperson with a few think tanks (depending on the country/region, 4-12). Think tanks were evaluated on the criteria of motivation, capacity (organisational, research and dissemination), impact and independence. Although most of the potential partners had not previously worked in the economics of tobacco control, it was essential that the partners displayed an interest in the research, and integration into the knowledge to policy process in tobacco tax reform. Policy engagement would require coordination with the tobacco control community to fill the need for policy relevant research and translation of the research findings into accessible briefings for advocates, policy makers and the media. Assessing this level of motivation is not a straightforward undertaking, but clearly expressing the scope of the research and dissemination activities required at the outset was helpful.

The Tobacconomics team also wanted to work with think tanks with sufficient organisational capacity and accountability mechanisms in place, especially since grant funds are restricted to research and dissemination activities. Other capacity indicators were economic researchers in the organisation with previous publications in scientific journals, and communications capacity within the organisation to ensure the research reached the intended audiences. Next, the think tank's policy impact was evaluated, indirectly measured through media coverage, policy changes subsequent to the research, participation of researchers on economic advisory panels, awards, other formal recognition of research, and so on. Finally, potential partners were vetted for tobacco industry influence and affiliation. This criterion eliminated many potential groups given that the tobacco industry funds hundreds of research institutions and individuals worldwide to produce research to block adoption of tobacco control policies, especially tobacco tax increases. ${ }^{11}$

After the scoping exercise, in 2018, the team established partnerships covering 22 think tanks including two regional networks. In all, as shown in figure 1 below, from 2017-2019, the Tobacconomics team developed the capacity of 27 different think tanks to conduct research, produce reports/briefs and present these results to other researchers, advocates and policy makers.

\section{How capacity building is delivered}

Before the start of the grant, after a research topic is selected, capacity building needs are assessed and appropriate trainings are scheduled in the first part of the year. Throughout the research process, Site Leads provide mentoring and technical assistance, both remotely and inperson through webinars, conference calls and inperson workshops. At least once a year, think tank partners in each region gather to share their research results with other think tanks and receive feedback. At these meetings, the think tanks also receive training on research dissemination methods.

In addition, the team produces Tobacconomics toolkits; the first of which, Using Household Expenditure Surveys for Research in Tobacco Economics has already been applied by researchers. For example, authors of one of the papers in this supplement from Vietnam applied the toolkit soon after its publication. Using the Vietnam Household Living Standard Survey data from 2012 to 2016, the authors found that tobacco spending decreases household expenditure on health, education and housing. The goal of the project is to produce toolkits covering each core competency for research on the economics of tobacco.

Another important aspect of capacity building for our think tank partners is educating them on the influence and tactics of the tobacco industry in the tobacco policy making process. Integrating the think tanks into the local tobacco control community has been helpful in this regard as tobacco control advocates are well acquainted with tobacco industry tactics and help in monitoring industry influence. Facilitating participation of the think tanks in tobacco control conferences at the national and regional levels where they interact with advocates and receive feedback on their research has helped the think tanks understand the need for policy relevant research.

\section{Situating the Tobacconomics capacity building approach}

The Tobacconomics capacity building approach falls in the middle ground between organisational core support and 


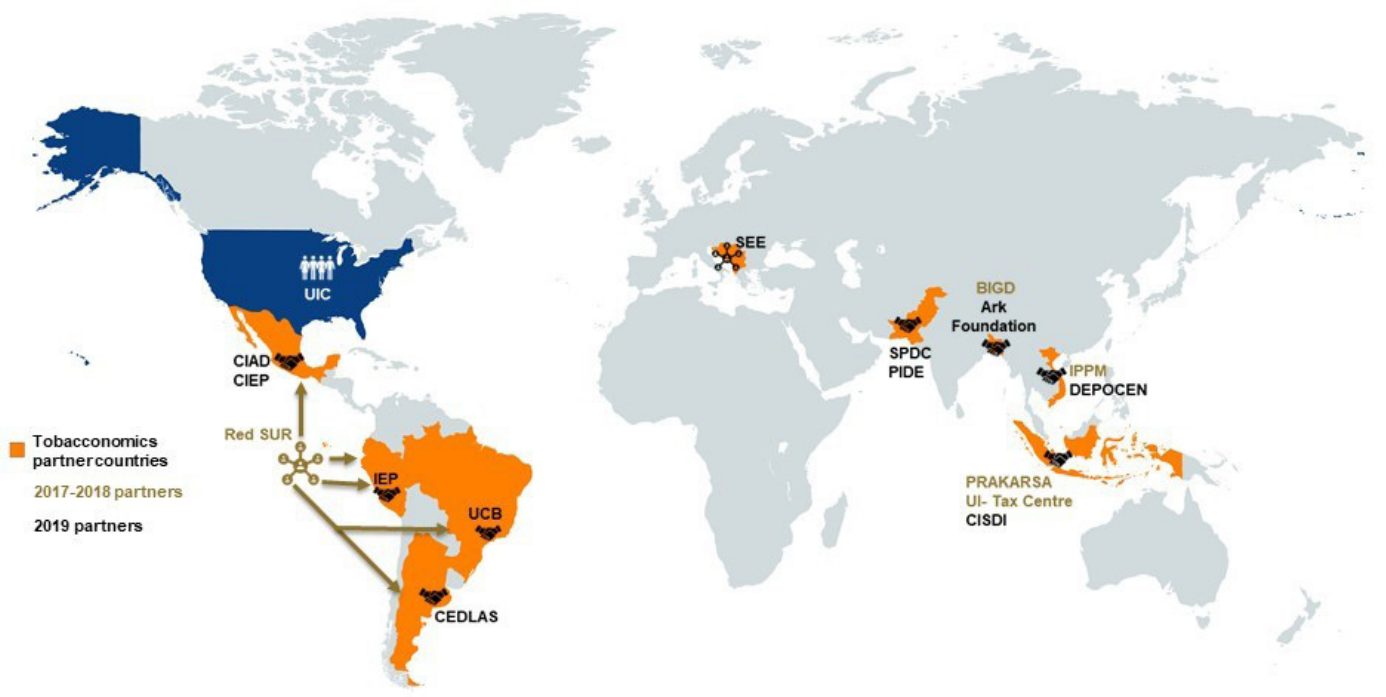

Figure 1 UIC partnerships in 2017-2019.

contracted research. Building the capacity of research institutions in LMICs to contribute to evidence-based policy making has been a priority for several large government-funded initiatives and organisations. These efforts have provided core support for policy research institutions to build organisation, policy engagement and research capacity with a principled focus on demand-led support. ${ }^{12}$ This trend has largely been a response to donor-funded initiatives on specific policy issues, often on short funding cycles, which can impede long-term capacity development. ${ }^{10}$ By partnering with local think tanks, the Tobacconomics team aims to establish a sustainable source of local evidence on tobacco economics with the capacity to contribute to evidencebased policy making beyond our involvement in the country/ region.

\section{CONCLUSION}

The articles contained within this supplement have been produced in the first cycle of this capacity building project on tobacco economics. It is hoped that the articles will stimulate further research in building the evidence base for effective tobacco tax policies as well as build long-term capacity in the countries from which the research emerges. For more information about Tobacconomics, or the project, visit Tobacconomics. org.

\section{Twitter Erika Siu @erikadayle}

Funding This study was funded by Bloomberg Philanthropies (Bloomberg Initiative To Reduce Tobacco Use).

Map disclaimer The depiction of boundaries on the map(s) in this article does not imply the expression of any opinion whatsoever on the part of BMJ (or any member of its group) concerning the legal status of any country, territory, jurisdiction or area or of its authorities. The map(s) are provided without any warranty of any kind, either express or implied.

Competing interests None declared.
Patient consent for publication Not required.

Provenance and peer review Not commissioned; externally peer reviewed.

ORCID iD

Erika Siu http://orcid.org/0000-0002-1274-2058

\section{REFERENCES}

1 Goodchild M, Nargis N, Tursan d'Espaignet E, et al. Modeling the impact of raising tobacco taxes on public health and finance. Bull World Health Organ 2016;95:250-7.

2 International Agency for Research on Cancer. IARC handbooks of cancer prevention: tobacco control, volume 14 - effectiveness of Tax and price policies for tobacco control (hereafter: IARC Handbook 14). Lyon, France: World Health Organization, International Agency for Research on Cancer, 2012.

3 U.S. National Cancer Institute and World Health Organization. The Economics of Tobacco and Tobacco Control. National Cancer Institute Tobacco Control Monograph 21. NIH Publication No. 16-CA-8029A. Bethesda, MD, Geneva, CH: U.S. Department of Health and Human Services, National Institutes of Health, National Cancer Institute; World Health Organization, 2016: 71-108.

4 U.S. National Cancer Institute and World Health Organization. The Economics of Tobacco and Tobacco Control. National Cancer Institute Tobacco Control Monograph 21. NIH Publication No. 16-CA-8029A. Bethesda, MD; Geneva, CH: U.S. Department of Health and Human Services, National Institutes of Health, National Cancer Institute; World Health Organization, 2016: 109-62.

5 World Health Organization. WHO report on the global tobacco epidemic, $2015-$ raising taxes on tobacco. Geneva, CH: World Health Organization, 2015.

6 Jones $\mathrm{H}$, Jones $\mathrm{N}$, Shaxson $\mathrm{L}$, et al. Knowledge, policy and power in international development: a practical framework for improving policy. background note, overseas development Institute 2013:9.

7 Measuring illicit trade in tobacco in low- and middle-income countries, 2020. Tobacco control. Available: https://tobaccocontrol.bmj.com/content/29/Suppl_4

8 Datta A, Sigdel S. North-South collaboration: eight tips for working with local think tanks. On Think Tanks 2016;LC:6.

9 Ubels J, Fowler A, Acquaye-Baddoo N-A, et al. Chapter range goes here. In: Capacity development in practice. London, Washington, DC: Earthscan, 2010.

10 Datta A, Shaxson L, Pellini A. Capacity, complexity and consulting: Lessons from managing capacity development projects. Working Paper 344. Overseas Development Institute, 2012.

11 Glenza J. Revealed: the Free-market groups helping the tobacco industry. The guardian 2019

12 Weyrauch V. Capacity development within the think tank initiative: a review with strategic recommendations. think tank initiative working papers series 2014. 